\title{
ACTA IMEKO: gaining momentum
}

\section{Paolo Carbone}

Department of Electronics and Information Engineering, University of Perugia, Via G. Duranti, 93 - 06125 Perugia, Italy

Citation: Paolo Carbone, ACTA IMEKO: gaining momentum, Acta IMEKO, vol. 2, no. 1, article 2, August 2013, identifier: IMEKO-ACTA-02(2013)-01-02

Editor: Paolo Carbone, University of Perugia, Italy

Copyright: @ 2013 IMEKO. This is an open-access article distributed under the terms of the Creative Commons Attribution 3.0 License, which permits unrestricted use, distribution, and reproduction in any medium, provided the original author and source are credited

Corresponding author: Paolo Carbone, e-mail: paolo.carbone@unipg.it

\section{INTRODUCTION}

After the journal kick-off last year, much has been done to produce this issue: many new people were involved to process incoming papers and an improved software infrastructure now guarantees sustainability of all operations. The publication process has been fine-tuned and many new papers are currently entering the production process.

ACTA IMEKO publishes extended papers that have been previously presented at workshops, congresses and symposia organized by IMEKO worldwide. It offers the opportunity to publish the outcomes of research activities, presented and discussed at conferences, to favour improvements. The amplitude of the topics treated within IMEKO, by its 24 Technical Committees guarantees a full coverage of the subjects of interest in metrology and of their applications. So, if you happen to present your scientific work in an IMEKO sponsored event, consider also the possibility to access ACTA IMEKO as your supporting medium for the extended version of your paper. The open access nature of this publication will guarantee maximum availability of your results, looking at the entire scientific world as a possible stakeholder.

As first Editor-in-chief of this scientific journal, I am very proud to introduce this issue, full of interesting contributions by scientists in the areas of Measurement of Electrical Quantities (TC4), Education and Training in Measurement and Instrumentation (TC1), Measurement Science (TC7), and Measurements in Biology and Medicine (TC13). Papers refer to two major IMEKO events that took place recently in Korea and Germany. Details on these symposia are provided in the introductions by the section editors of this issue, Ján Šaliga, Dušan Agrež and Gerhard Linß.

Many people have contributed to this issue under the supervision of the IMEKO Vice-president for publications, Paul Regtien. Beyond the valuable contributions of all involved reviewers, in particular Francisco Alegria, Pedro Ramos, Sergio Rapuano and Dirk Röske did all an excellent and effective job in making this publication possible. Thank you to all of them.

Keep in touch with our journal and enjoy its scientific content. 